\begin{tabular}{|c|c|c|c|}
\hline Pnartc & Case Rep Gastroenterol 2018; & & \\
\hline $0109 y$ & $\begin{array}{l}\text { DOI: 10.1159/000493183 } \\
\text { Published online: November 28, } 2018\end{array}$ & $\begin{array}{l}\text { (c) } 2018 \text { The Author(s) } \\
\text { Published by S. Karger AG, Basel } \\
\text { www.karger.com/crg }\end{array}$ & $\begin{array}{l}\text { Karger } \\
\text { Open'access }\end{array}$ \\
\hline & $\begin{array}{l}\text { This article is licensed under the } \mathrm{C} \\
\text { International License (CC BY-NC) (h } \\
\text { Usage and distribution for commercial }\end{array}$ & $\begin{array}{l}\text { nons Attribution-NonCommerc } \\
\text { ger.com/Services/OpenAccessLi } \\
\text { uires written permission. }\end{array}$ & \\
\hline
\end{tabular}

\title{
Severe Diarrhea in the Setting of Immune Checkpoint Inhibitors
}

\author{
Jean R. Kuo ${ }^{a}$ Amy D. Davis ${ }^{b} \quad E^{2}$ duardo A. Rodriguez ${ }^{a} \quad$ Marcelo F. Vela $^{a}$ \\ Russell I. Heigh ${ }^{a}$ Marcela A. Salomao ${ }^{c}$ Suryakanth R. Gurudu ${ }^{a}$ \\ aDivision of Gastroenterology and Hepatology, Mayo Clinic Arizona, Scottsdale, AZ, USA; \\ ${ }^{b}$ Department of General Internal Medicine, Mayo Clinic Arizona, Scottsdale, AZ, USA; \\ 'Department of Laboratory Medicine and Pathology, Mayo Clinic Arizona, \\ Scottsdale, AZ, USA
}

\section{Keywords}

Diarrhea - Immune checkpoint inhibitors · Microscopic colitis · Ipilimumab colitis · Crohn's disease $\cdot$ Clostridium difficile

\begin{abstract}
Immune checkpoint inhibitors (ICPIs) are novel therapeutic agents targeting a variety of cancers by enhanced T cell activation. Immune-related adverse events (irAEs) commonly occur with ICPI use and can affect multiple organ systems including the gastrointestinal tract. Due to irAEs, the use of ICPIs is limited in autoimmune diseases. We present a case of microscopic colitis diagnosed after the initiation of nivolumab and a case of ipilimumab colitis and Clostridium difficile in the setting of Crohn's colitis.

(C) 2018 The Author(s) Published by S. Karger AG, Basel
\end{abstract}

\section{Introduction}

Immune checkpoint inhibitors (ICPIs) are novel immunotherapy agents that are used to treat an increasingly wider array of cancers. ICPIs were initially used in metastatic melanoma and are now used in multiple malignancies [1,2]. There are two categories of ICPIs that are currently used in clinical practice: anti-cytotoxic T-lymphocyte antigen 4 (anti-CTLA-4) antibodies and anti-programmed cell death-protein 1 (anti-PD-1) antibodies. Anti-CTLA-4 


\section{Case Reports in Gastroenterology}

Case Rep Gastroenterol 2018;12:704-708

DOI: $10.1159 / 000493183$

(c) 2018 The Author(s). Published by S. Karger AG, Basel www.karger.com/crg

Kuo et al.: Severe Diarrhea in the Setting of Immune Checkpoint Inhibitors

antibodies include ipilimumab (Yervoy). Anti-PD-1 antibodies include nivolumab (Opdivo) and pembrolizumab (Keytruda). ICPIs increase T cell activation which can then lead to immune related adverse events, including those of the gastrointestinal tract [2]. We present 2 cases of severe diarrhea in the setting of ICPIs and autoimmune disease.

\section{Case Reports}

Case 1

A 74-year-old male with a history of metastatic pulmonary squamous cell carcinoma was admitted with 2 weeks of severe diarrhea. He had been started on second-line nivolumab 9 months prior to admission. He was only able to complete 10 cycles as he developed diarrhea that initially responded to steroids. On admission, he reported 10-15 episodes of large-volume watery stools per day without mucus, blood or significant abdominal pain. Stool studies for bacteria, viruses, and parasites were negative, and a fecal lactoferrin was positive. Computed tomography (CT) of the abdomen/pelvis with contrast showed mild mural thickening of the inferior cecum and terminal ileum. A colonoscopy was notable for a few 3- to 5-mm ulcerations scattered through entire colon and a 5-mm flat polypoid lesion in the transverse colon. Random biopsies including those of the polyp and ulcers were obtained. Pathology demonstrated preserved crypt architecture, marked propria lymphoplasmacytic inflammation, diffuse intraepithelial lymphocytosis, and marked increase in subepithelial collagen deposition (Fig. 1a). These features were consistent with collagenous colitis. The patient required two budesonide tapers starting at $9 \mathrm{mg}$ daily for his diarrhea, and nivolumab was not restarted. Although the patient was started on docetaxel, he unfortunately had progression of his disease and ultimately died in hospice.

Case 2

A 68-year-old female with a history of stage III melanoma presented to her oncologist with diarrhea of 1 month's duration. An abdomen/pelvis CT revealed mucosal thickening of the terminal ileum. A colonoscopy noted mild inflammation from the transverse colon to cecum, sigmoid colon to descending colon, and moderate inflammation in the rectum. Biopsies of her terminal ileum and colon were consistent with Crohn's disease. She was referred to Gastroenterology and was started on mesalamine $2.4 \mathrm{~g}$ twice daily. She was then initiated on first-line pembrolizumab. A month after starting pembrolizumab, the patient was hospitalized for acute on chronic diarrhea. Her CT abdomen/pelvis and flexible sigmoidoscopy demonstrated nonspecific active chronic colitis. She improved with intravenous methylprednisolone $20 \mathrm{mg}$ three times daily, transitioned to prednisone $40 \mathrm{mg}$ daily, and eventually to a budesonide taper. Six months later, the patient was started on ipilimumab and nivolumab due to progression of her melanoma. The patient developed bloody diarrhea 3 days after initiating the new combination therapy. Repeat flexible sigmoidoscopy demonstrated severe inflammation from the rectum to the splenic flexure concerning for worsened colitis. Her pathology was notable for marked inflammation, cryptitis, and crypt cell apoptosis which was consistent with ipilimumab colitis (Fig. 1b). Her diarrhea improved with two doses of infliximab $200 \mathrm{mg}$ and intravenous methylprednisolone $20 \mathrm{mg}$ three times daily transitioned to a prednisone taper. One month later, she received another dose of the combination immunotherapy and experienced similar symptoms of diarrhea the following day. She also tested positive for Clostridium difficile. She was treated with oral vancomycin $250 \mathrm{mg}$ every $6 \mathrm{~h}$, intravenous 


\section{Case Reports in Gastroenterology}

Case Rep Gastroenterol 2018;12:704-708 DOI: $10.1159 / 000493183$

(c) 2018 The Author(s). Published by S. Karger AG, Basel www.karger.com/crg

Kuo et al.: Severe Diarrhea in the Setting of Immune Checkpoint Inhibitors

hydrocortisone $20 \mathrm{mg}$ three times daily, and another slow prednisone taper. Unfortunately, she continued to decline and ultimately died in hospice.

\section{Discussion}

ICPIs work primarily by inhibiting T-cell inhibitory signals and lead to increased $\mathrm{T}$ cell activation which then leads to increased anti-tumor T-cell response [2]. Due to increased T cell activation, autoimmune-like adverse events can occur. These autoimmune-like adverse events have been labelled immune-related adverse events (irAEs) [2]. irAEs most commonly affect the skin and gastrointestinal organ systems. Gastrointestinal irAEs include diarrhea, colitis, hepatotoxicity, pancreatitis, esophagitis, and inflammatory enteric neuropathy with constipation $[3,4]$. Life-threatening consequences such as perforation have also been described [2].

Gastroenterologists are typically consulted when patients develop significant diarrhea. CT abdomen/pelvis can demonstrate evidence of colitis with bowel wall thickening and mesenteric engorgement [2]. After ruling out infectious etiologies of diarrhea such as $C$. difficile, colonoscopy is typically pursued. On colonoscopy, the findings are nonspecific and can range from normal mucosa to ulceration of the colon and ileum [5, 6]. Typically, lesions are predominately in the descending colon $[2,3]$. On biopsy, neutrophilic and lymphocytic infiltrates as well as cryptitis and crypt abscesses have been described [5, 7-9].

After diagnosing immune-related enterocolitis, patients should be started on high-dose steroid therapy. If the patient remains refractory to high-dose steroids, infliximab can be considered. If the patient continues to have significant diarrhea refractory to steroids and infliximab, tacrolimus or mycophenolate mofetil are also utilized. In severe cases, colectomy may be required [2].

Due to the autoimmune-like process of ICPIs, aggravation of known inflammatory conditions or discovery of occult inflammatory conditions has also been described. There have been 2 case reports of microscopic colitis diagnosed after the initiation of pembrolizumab and ipilimumab $[10,11]$. In addition, there have been 3 case reports of ICPI use in Crohn's disease. In one patient, there was a possible flare of Crohn's disease after a patient was started on pembrolizumab for metastatic colon cancer [12]. In another patient, ipilimumab-induced colitis was diagnosed in a patient with Crohn's disease on ipilimumab for metastatic melanoma [13]. Finally, in a separate patient, an intra-abdominal abscess concerning for Crohn's disease flare was diagnosed in a patient with Crohn's disease on pembrolizumab [14].

We describe the first case of microscopic colitis after the initiation of nivolumab. In addition, we describe a case of ipilimumab colitis and C. difficile in the setting of Crohn's disease. Our cases highlight the importance of investigating a broad differential when managing patients with diarrhea on ICPIs.

\section{Statement of Ethics}

Both patients described were deceased by the time of abstract submission. Consent was obtained from the first patient's wife. The emergency contact for the second patient was unable to be reached. 


\section{Case Reports in Gastroenterology}

Kuo et al.: Severe Diarrhea in the Setting of Immune Checkpoint Inhibitors

\section{Disclosure Statement}

Suryakanth R. Gurudu receives grant support from Gilead Sciences, but there are no other conflicts of interest.

\section{References}

1 Gonzalez RS, Salaria SN, Bohannon CD, Huber AR, Feely MM, Shi C. PD-1 inhibitor gastroenterocolitis: case series and appraisal of 'immunomodulatory gastroenterocolitis'. Histopathology. 2017 Mar;70 (4):558-67.

2 Spain L, Diem S, Larkin J. Management of toxicities of immune checkpoint inhibitors. Cancer Treat Rev. 2016 Mar;44:51-60.

3 Pernot S, Ramtohul T, Taieb J. Checkpoint inhibitors and gastrointestinal immune-related adverse events. Curr Opin Oncol. 2016 Jul;28(4):264-8.

4 Villadolid J, Amin A. Immune checkpoint inhibitors in clinical practice: update on management of immunerelated toxicities. Transl Lung Cancer Res. 2015 Oct;4(5):560-75.

5 Oble DA, Mino-Kenudson M, Goldsmith J, Hodi FS, Seliem RM, Dranoff G, et al. Alpha-CTLA-4 mAb-associated panenteritis: a histologic and immunohistochemical analysis. Am J Surg Pathol. 2008 Aug;32(8):1130-7.

6 Berman D, Parker SM, Siegel J, Chasalow SD, Weber J, Galbraith S, et al. Blockade of cytotoxic T-lymphocyte antigen- 4 by ipilimumab results in dysregulation of gastrointestinal immunity in patients with advanced melanoma. Cancer Immun. 2010 Nov; 10:11.

7 Bertrand A, Kostine M, Barnetche T, Truchetet ME, Schaeverbeke T. Immune related adverse events associated with anti-CTLA-4 antibodies: systematic review and meta-analysis. BMC Med. 2015 Sep;13(1):211.

8 Chen JH, Pezhouh MK, Lauwers GY, Masia R. Histopathologic Features of Colitis Due to Immunotherapy With Anti-PD-1 Antibodies. Am J Surg Pathol. 2017 May;41(5):643-54.

9 Marthey L, Mateus C, Mussini C, Nachury M, Nancey S, Grange F, et al. Cancer Immunotherapy with AntiCTLA-4 Monoclonal Antibodies Induces an Inflammatory Bowel Disease. J Crohn's Colitis. 2016 Apr;10(4):395-401.

10 Baroudjian B, Lourenco N, Pagès $C$, Chami I, Maillet M, Bertheau P, et al. Anti-PD1-induced collagenous colitis in a melanoma patient. Melanoma Res. 2016 Jun;26(3):308-11.

11 García-Varona A, Odze RD, Makrauer F. Lymphocytic colitis secondary to ipilimumab treatment. Inflamm Bowel Dis. 2013 Feb;19(2):E15-6.

12 Esfahani K, Miller WH Jr. Reversal of Autoimmune Toxicity and Loss of Tumor Response by Interleukin-17 Blockade. N Engl J Med. 2017 May;376(20):1989-91.

13 Gielisse EA, de Boer NK. Ipilimumab in a patient with known Crohn's disease: to give or not to give? J Crohn's Colitis. 2014 Dec;8(12):1742.

14 Uemura M, Trinh VA, Haymaker C, Jackson N, Kim DW, Allison JP, et al. Selective inhibition of autoimmune exacerbation while preserving the anti-tumor clinical benefit using IL- 6 blockade in a patient with advanced melanoma and Crohn's disease: a case report. J Hematol Oncol. 2016 Sep;9(1):81. 

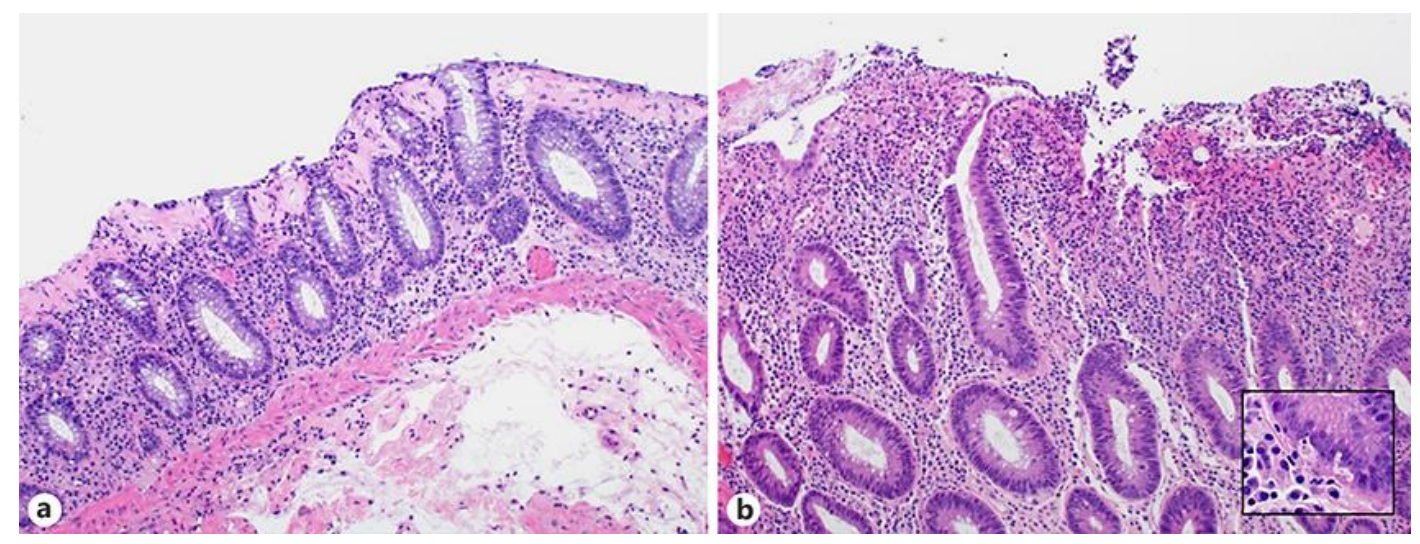

Fig. 1. a Colonic biopsy demonstrating marked thickening of subepithelial collagen layer, consistent with collagenous colitis. b Colonic biopsy demonstrating marked inflammation, cryptitis, and crypt cell apoptosis. Inset demonstrates increase in crypt cell apoptosis. Hematoxylin and eosin-stained biopsy specimens at $\times 100$ magnification, inset at $\times 400$ magnification. 